\title{
PENERAPAN REKAYASA NILAI PADA PRODUK SPRING BED TIPE ROMANO
}

\author{
Fery Yulianto*)
}

\begin{abstract}
"UD. Dominico", Pasuruan forms the enterprise of furniture sector. But, the condition of design and facility of spring bed, type of romano cannot give satisfaction enough to the customer, especially the design and facility. In this case, there are some complaints from the customer, so volume of spring bed sale decreased. The problem took how to make a planning of design and facility of spring bed, especially type of "Romano".

The application of Value Engineering is the way to solve a problem above with terms that have determined or recomanded.

Five phase of work planning in application of Value Engineering method can be solved by this intergration that are :

1. Information phase

2. Analysis phase

3. Creative phase

4. Development phase

5. Presentation phase

Based on the result of analysis and calculation by using the study of Value Engineering, the result is comparative between the fist condition and suggestion condition. Because there is an addition of design function and facility of spring bed. It can be obtained five design alternatives and spring bed facility from five elements, that are esthetics, high construction, comfortable, cover material and practical.

The result of spring bed analysis alternative are :

- Suggestion Alternative, performance $=51,1842$

- First Alternative, performance $\quad=42,2395$

$$
\text { Value }=1,5288
$$$$
\text { Value }=1
$$

Key word : Value Engineering, Spring Bed Alternative

\section{A. PENDAHULUAN}

Dengan melihat perkembangan meubel yang begitu pesat akhir-akhir ini dalam hal ini "UD.Dominico" harus bisa menghasilkan produk yang bisa bersaing di pasaran. Dengan desain produk yang menarik dan bahan yang berkualitas diharapkan produk yang dihasilkan akan bisa memenuhi selara dari konsumen.

Di "UD.Dominico" mengalami permasalahan pada produknya, dimana spring bed tipe romano ukuran $180 \mathrm{~cm}$ modelnya monoton dan kurang memenuhi selera konsumen.

\footnotetext{
${ }^{*}$ Karyawan PT Pindad.
}

Pada data yang lalu model spring bed tipe romano ini sangat digemari, tetapi sejalan dengan perkembangan zaman yang ada, spring bed tipe romano saat ini sudah dianggap ketinggalan zaman, sehingga perlu adanya peningkatan desain produk yang memperlihatkan keseimbangan antara value engineering, perbandingan performansi serta biaya yang berorientasi pada fungsi produk yang dihasilkan.

Adapun data penjualan di "UD.Dominico" adalah sebagai berikut : 
Tabel 1

Data Penjualan Spring Bed Tipe Romano Ukuran $(180 \mathrm{~cm})$

\begin{tabular}{|c|c|}
\hline Bulan & Jumlah \\
\hline Juni 2001 & 22 \\
\hline Juli 2001 & 20 \\
\hline Agustus 2001 & 17 \\
\hline September 2001 & 20 \\
\hline Oktober 2001 & 16 \\
\hline November 2001 & 14 \\
\hline Desember 2001 & 15 \\
\hline Januari 2002 & 11 \\
\hline Februari 2002 & 10 \\
\hline Maret 2002 & 8 \\
\hline April 2002 & 10 \\
\hline Mei 2002 & 9 \\
\hline
\end{tabular}

Juni 2001 - Mei 2002

Sumber : "UD.DOMINICO"PASURUAN

\section{Tujuan}

1. Mendapatkan rancangan alternatif produk yang sesuai dengan keinginan konsumen.

2. Mendapatkan peningkatan nilai desain produk setelah penerapan value engineering.

\section{B. LANDASAN TEORI}

\section{Definisi dan Pengertian Rekayasa Nilai}

Rekayasa Nilai adalah suatu pendekatan yang bersifat kreatif dan sistematis dengan tujuan mengurangi atau menghilangkan biaya-biaya yang tidak diperlukan. (Lawrence D. Miles)

\section{Prinsip Dasar Rekayasa Nilai}

Tujuan Rekayasa Nilai adalah mendapatkan nilai (value) semaksimal mungkin, secara sederhana value dapat dinyatakan sebagai berikut :

$$
V_{\text {max }}=\frac{F}{C_{\text {min }}}
$$

Dimana : $\mathrm{V}_{\max }=$ nilai maksimal, $\mathrm{C}_{\min }=$ Biaya minimal dan $\mathrm{F}=$ Fungsi.
Fungsi disini bisa juga dinyatakan dengan kata benda dan kata sifat, jadi untuk nilai $\mathrm{V}$ bisa juga dinyatakan sebagai berikut :

$$
V=\frac{\text { Performance }}{\text { Biaya }}
$$

Nilai dinyatakan sebagai perbandingan antara performansi yang diberikan oleh sistem yang sedang didesain dengan jumlah biaya untuk mengadakan fungsi-fungsi yang diberikan oleh desain.

\section{Rencana Kerja Rekayasa Nilai}

Rencana kerja adalah pendekatan yang merupakan kerangka dimana teknik-teknik rekayasa nilai saling terkait antara satu sama lain. Rencana kerja rekayasa nilai terdiri atas lima tahap yaitu :

1. Tahap Informasi

2. Tahap Kreatif

3. Tahap Analisa

4. Tahap Pengembangan

5. Tahap Presentasi

Setiap tahap ini mempunyai tujuan masingmasing. Gambar 1 menjelaskan hubungan antara masing-masing tahap dalam rencana kerja rekayasa nilai.

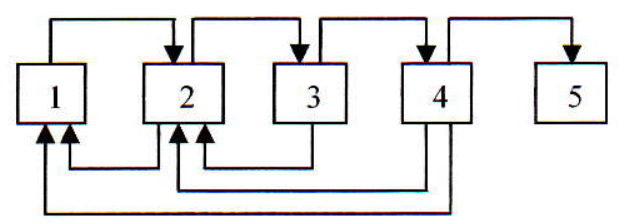

Gambar 1

Hubungan kelima fase kerja Rekayasa Nilai Teknik-Teknik Dalam Rekayasa Nilai 
Teknik-teknik yang biasa digunakan dalam rencana kerja setiap fase adalah :

1. Fase informasi

- Kuisioner

- Peramalan

- Wawancara

- Riset Pasar

- Metode Fast

\begin{tabular}{|l|lr|}
\hline $\begin{array}{l}\text { Sumber } \\
\text { Data }\end{array}$ & $\begin{array}{l}\text { Data primer dan data } \\
\text { sekunder }\end{array}$ \\
\hline Instrumen & $\begin{array}{l}\text { Literatur, interview, } \\
\text { observasi serta } \\
\text { dokumentasi. }\end{array}$ \\
\hline Analisa Data & $\begin{array}{l}\text { Analisa keuntungan } \\
\text { kerugian, analisa matrik } \\
\text { kelayakan, analisa matrik } \\
\text { evaluasi, perhitungan } \\
\text { performansi, biaya dan } \\
\text { nilai. }\end{array}$ \\
\hline
\end{tabular}

2. Fase Kreatif

- Analisa morfologis

- Brainstorning

- Check List

3. Fase Analisa

- Matriks Evaluasi

- Metode Zero-One

- Proses hierarki Analitik

- Analisa Atribut

\section{METODE}

Rancangan penelitian yang digunakan adalah sebagai berikut :

Tabel 2

Rancangan Penelitian

\begin{tabular}{|c|c|}
\hline $\begin{array}{c}\text { Rancangan } \\
\text { Penelitian }\end{array}$ & Proses Pengolahan \\
\hline Sampel & $\begin{array}{l}\text { Diambil dari data-data } \\
\text { yang mempunyai kaitan } \\
\text { dengan } \\
\text { Engineering Value } \\
\text { menaikkan performansi, untuk } \\
\text { menekan biaya dan } \\
\text { meningkatkan nilai yang } \\
\text { berupa data fasilitas yang } \\
\text { ada, kuisioner } \\
\text { pembobotan kriteria, } \\
\text { kuisioner evaluasi, serta } \\
\text { biaya-biaya yang } \\
\text { dibebankan untuk } \\
\text { penerapan desain awal }\end{array}$ \\
\hline
\end{tabular}

\section{Sumber Data}

1. Data Primer

Data yang dikumpulkan sendiri atau langsung dari sumber utama

2. Data Sekunder

Data yang diperoleh dari orang lain dan secara tidak langsung dalam hal ini data sekunder berupa dokumen-dokumen dan data-data lain dari perusahaan.

\section{Pengumpulan Data}

1. Library Reseach

Cara pengambilan data dari literaturliteratur yang berhubungan dengan pokok-pokok pembahasan penelitian.

2. Field Research ( Penelitian Lapangan )

Suatu metode pengambilan data dengan mendatangi langsung obyek-obyek yang berkaitan erat dengan pembahasan penelitian. Pengumpulan data bisa dilakukan dengan cara sebagai berikut :

Observasi, yaitu : Cara pengambilan data dengan cara melakukan pengamatan secara langsung pada obyek yang diamati.

Interview (wawancara), yaitu : Bentuk pengambilan data dengan wawancara langsung 
terhadap orang- orang yang terlibat dengan obyek penelitian.

\section{ANALISA}

\section{Kriteria Kebutuhan}

Dari wawancara terhadap 10 orang ahli didapatkan kriteria-kriteria kebutuhan sebagai berikut :

1. Sebagai Tempat tidur

Dasar pertimbangan terhadap kriteria ini adalah ditentukan oleh bahan yang digunakan dimana kain yang digunakan tidak panas dan busa yang lembut.

\section{Sebagai Syarat kesehatan}

Dasar pertimbangan terhadap kriteria ini adalah ditentukan oleh kenyamanan dan keamanan dari spring bed

3. Sebagai Nilai Estetika

Dasar pertimbangan terhadap kriteria ini ditentukan oleh bentuk desain, perpaduan antara model dan warna.

\section{Struktur Fungsi Spring Bed}

Untuk mendapatkan struktur fungsi dari spring bed digunakan Metode fast, yaitu:

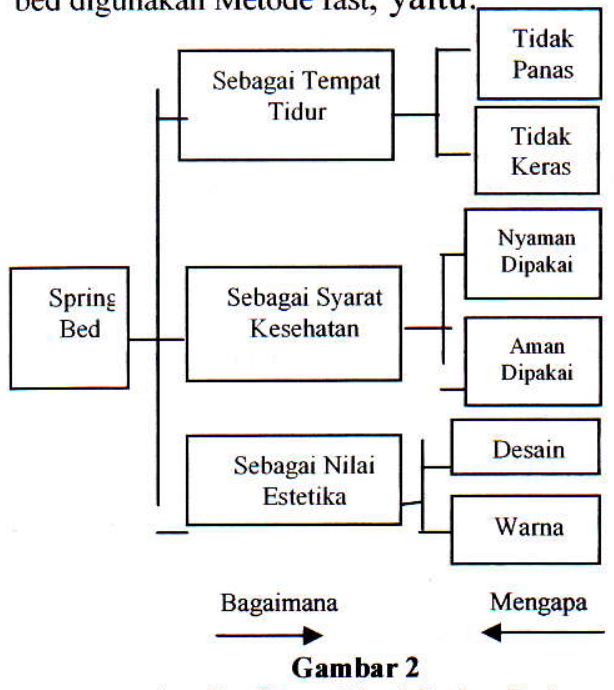

Analisa Fungsi Dari Spring Bed Data Material
Data material yang digunakan dalam pembuatan spring bed adalah :

1. Kayu Rangka 10. Benang

2. Karet 11. Pita Luar

3. Pegas 12. Mika

4. Busa/Spon 13. Plastik

5. Karton 14. Lem

6. Kain Cover 15. Paku List

7. Kain Tutup 16. Paku Ban

8. Cop Stabil 17. Paku Cop

9. Kor Dalam

\section{Penentuan Tingkat Kontribusi Masing-Masing}

\section{Kriteria}

Dari data yang diperoleh melalui kuisioner, dilakukan pengolahan data untuk menentukan tingkat kontribusi masing-masing parameter.

$$
\% \text { Kriteria } \quad(K r)=\frac{K i}{\sum K i} \times 100 \%
$$

Dimana $\mathbf{I}=1,2,3 \ldots ., 5$

Perhitungan kontribusi untuk kriteria estetika adalah sebagai berikut :

$$
\% \text { Kriteria }(\mathrm{Kr})=\frac{1677}{8295} \times 10 \%
$$

$\%$ Kriteria $(\mathrm{kr})=20.22$

Dengan cara perhitungan yang sama untuk perhitungan kriteria yang lain. Adapun hasil perhitungan untuk penentuan tingkat kontribusi masing-masing parameter adalah sebagai berikut terlihat pada tabel 3

Tabel 3

Nilai Kontribusi tiap Parameter

\begin{tabular}{|l|c|}
\hline Parameter Kriteria & \% \\
\hline Estetika & 20,22 \\
Kontruksi Kuat & 19,17 \\
Nyaman dipakai & 25,68 \\
Kain Cover & 20,10 \\
Praktis & 14,88 \\
\hline
\end{tabular}


Tetapi telah dilakukan pengurutan (rangking) yang dapat dilihat pada tabel 4.

Tabel 4

Ranking Nilai Kontribusi Masing-masing Parameter

\begin{tabular}{|l|c|}
\hline Parameter kriteria & \% \\
\hline Nyaman dipakai & 25,68 \\
Estetika & 20,22 \\
Kain Cover & 20,10 \\
Kontruksi Kuat & 19,17 \\
praktis & 14,88 \\
\hline
\end{tabular}

\section{Menentukan Matrik Perbandingan \\ Berpasangan}

Matrik perbandingan berpasangan diperoleh dengan cara melakukan perbandingan berpasangan diperoleh masing-masing parameter.

Hasil perbandingan berpasangan antara masing-masing parameter dibentuk menjadi bujur sangkar dengan ordo sesuai dengan jumlah elemen parameter.

\section{Tabel 5}

Matrik Perbandingan Berpasangan

\begin{tabular}{|c|ccccc|}
\hline $\begin{array}{c}\text { Para- } \\
\text { meter }\end{array}$ & $\mathbf{1}$ & $\mathbf{2}$ & $\mathbf{3}$ & $\mathbf{4}$ & $\mathbf{5}$ \\
\hline 1 & 1 & 3 & 7 & 2 & 9 \\
2 & $1 / 3$ & 1 & 4 & 6 & 2 \\
3 & $1 / 7$ & $1 / 4$ & 1 & 5 & 4 \\
4 & $1 / 2$ & $1 / 6$ & $1 / 5$ & 1 & 3 \\
5 & $1 / 9$ & $1 / 2$ & $1 / 4$ & $1 / 3$ & 1 \\
\hline
\end{tabular}

\section{Menentukan Matrik Eigen Vektor}

Elemen-elemen pada masing-masing baris dari matrik hasil perbandingan berpasangan dikalikan secara kumulatif. Kemudian hasil perkalian dimasukkan dalam akar dengan derajat yang sesuai dengan jumlah elemen pada baris matrik.

Misalkan menentukan parameter desain interior dengan matrik baris 1,2,3,7,9 maka matrik kolom $=(1 \times 3 \times 7 \times 2 \times 9)^{1 / 5}=3,277$

Dengan cara perhitungan yang sama untuk perhitungan yang lain dapat dilihat pada lampiran 2. Dengan cara yang sama akan diperoleh matrik kolom untuk menentukan matrik eigen vektor, diperoleh dengan cara membagi matrik kolom. Misalnya untuk elemen eigen vektor baris (1) = $3,277 / 6,843=0,479$.

Dengan cara perhitungan yang sama untuk perhitungan yang lain dapat dilihat pada lampiran 2. Dengan cara yang sama maka akan diperoleh matrik eigen vektor.

\section{Matrik Kolom Matrik eigen vektor}

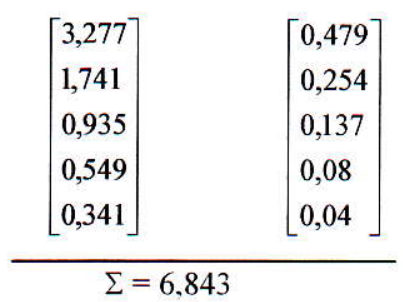

\section{Menentukan Eigen Value Maksimum}

Pertama kali ditentukan matrik kolom baru, yang dapat perkalian antara matrik perbandingan berpasangan dengan matrik eigen vektor. Selanjutnya menentukan eigen value yang merupakan hasil bagi antara elemen yang bersesuaian dari matrik kolom baru dengan eigen vektor. Misalnya untuk harga elemen matrik kolom baru baris $(1)=(1 \times 0,479)+(3 \times 0,254)+$ $(7 \times 0,137)+(2 \times 0,08)+(9 \times 0,04)=2,72$. 
Dengan cara yang sama diperoleh matrik kolom baru eigen value ( $\lambda$ maksimum) diperoleh rata-rata matrik eigen vector:

$\lambda$ maksimum $=\frac{\Sigma \text { Matrik EigenValue }}{\mathrm{n}}$

$\lambda$ maksimum $=\frac{25,139}{5}=5,0278$

\section{Penentuan Bobot Fungsi}

Dalam penentuan bobot fungsi dipergunakan metode analisis hierarki, yaitu dengan cara membandingkan fungsi-fungsi yang mempunyai tingkatan hierarki yang sama. Hal ini dilakukan terhadap seluruh fungsi pada setiap tingkatan hierarki yang terdapat dalam struktur fungsi.

Untuk memperoleh bobot fungsinya, disusun matrik perbandingan berpasangan dengan ordo yang sesuai dengan jumlah fungsi pada tingkatan hierarki yang sama. Selanjutnya dilakukan perhitungan nilai eigen vektor. Nilai eigen vektor inilah yang dilakukan sebagai bobot dari fungsi yang bersangkutan.

Berdasarkan hasil perhitungan yang ada, maka dapat kita peroleh bobot fungsinya adalah sebagai berikut :

1. b11 (fungsi tidak panas)

2. b21 (fungsi tidak keras)

3. b21 (fungsi nyaman dipakai)

4. b22 (fungsi aman dipakai)

5. b31 (fungsi desain)

6. b32 (fungsi warna)

7. b1 (fungsi tempat tidur)

8. b2 (fungsi syarat kesehatan)

9. b3 (fungsi estetika)

Dalam melakukan analisa dan desain peningkatan kualitas spring bed, perlu melibatkan sebanyak mungkin fungsi dari desain spring bed tersebut, sehingga mendapatkan suatu desain spring bed yang berkualitas.

Pemilihan desain terbaik berdasarkan pada estimasi nilai tertinggi dari alternatif desain. Nilai ini dinyatakan sebagai perbandingan rasio antara performansi yang diberikan oleh spring bed dan biaya-biaya yang dikeluarkan untuk mengadakan fungsi-fungsi yang diberikan oleh desain spring bed.

Besarnya performansi didapatkan berdasarkan hasil pengolahan data oleh masing-masing elemen sistem untuk tiap alternatif desain. Sedangkan biaya yang dipergunakan adalah biaya yang dikeluarkan untuk proses produksi.

\section{Menguji Konsistensi Data}

Untuk menguji konsistensi data diketahui dari nilai ratio konsistensi (CR). yang merupakan hasil bagi antara indeks konsistensi (CI) dengan indeks random $(\mathrm{RI})$.

$$
\begin{aligned}
C I & =\frac{\lambda_{\text {maks }}-n}{n-1} \\
& =\frac{5,0278-5}{5-1}=0,00695 \\
C R & =\frac{C I}{I R} \\
& =\frac{0,00695}{1,12}=0,00620
\end{aligned}
$$

Jika nilai $\mathrm{CR}<=0,10$ maka dapat dianggap konsisten.

Pemilihan desain terbaik berdasarkan pada estimasi nilai tertinggi dari alternatif desain. Nilai ini dinyatakan sebagai perbandingan rasio antara performansi dan biaya yang dikeluarkan untuk mengadakan fungsi-fungsi yang diberikan oleh desain spring bed. Besarnya performansi 
berdasarkan hasil pengolahan data oleh masingmasing elemen sistem untuk tiap alternatif desain.

\section{Alternatif Desain}

Berdasarkan dari analisa kebutuhan dan analisa fungsi, maka untuk mendapatkan produk spring bed yang diinginkan terdapat 3 macam permasalahan elemen yang dibutuhkan, yaitu : Elemen Bentuk, Elemen Bahan, Elemen Warna.

Pembangkit alternatif desain yang akan dimunculkan adalah sebagai berikut :

Tabel 5.2

\section{Pembangkit alternatif Desain}

\begin{tabular}{|c|c|c|c|c|c|c|}
\hline Elemen & \multicolumn{6}{|c|}{ Atribut/Alternatif } \\
\hline Bentuk & A & B & $\mathrm{C}$ & $\mathrm{D}$ & $\bar{E}$ & $\mathrm{~F}$ \\
\hline Sandaran & $A M 1$ & $A M 2$ & $A M 3$ & $A M 4$ & $A M 5$ & AM 6 \\
\hline Warna & G & $\mathrm{H}$ & I & $\mathrm{J}$ & K & \\
\hline Kain & Biru & Hitam & Hijau & Krem & Putih & \\
\hline \multirow[t]{2}{*}{ Cover } & Kombinasi & Kombinasi & Kombinasi & Kombinasi & Kombinasi & \\
\hline & Kuning & Emas & Kuning & Coklat & Pink & \\
\hline Tebal & L & $\mathrm{M}$ & $\mathrm{N}$ & & & \\
\hline Busa & $7 \mathrm{~cm}$ & $8 \mathrm{~cm}$ & $9 \mathrm{~cm}$ & & & \\
\hline Jumlah & $\mathrm{O}$ & $P$ & Q & & & \\
\hline Pegas & 130 buah & 140 buah & 150 buah & & & \\
\hline Jenis & $\mathrm{R}$ & $\mathrm{S}$ & & & & \\
\hline Kain & Kain Titan & Kain Rayon & & & & \\
\hline Cover & & & & & & \\
\hline
\end{tabular}

\section{Keterangan tabel :}

Bentuk sandaran : A,B,C,D,E,F (lihat gambar dalam lampiran)

Warna : $\mathrm{G}=$ Biru kombinasi kuning $\mathrm{H}=$ Hitam kombinasi emas I = Hijau kombinasi kuning $\mathbf{J}=$ Krem kombinasi coklat
$\mathrm{K}=$ Putih kombinasi pink

Tebal busa: $\mathrm{L} \quad=7 \mathrm{~cm}$

$$
\begin{aligned}
M & =8 \mathrm{~cm} \\
N & =9 \mathrm{~cm}
\end{aligned}
$$

$$
\begin{aligned}
\text { Jumlah pegas } \quad \mathrm{O} & =130 \text { buah } \\
\mathrm{P} & =140 \text { buah } \\
\mathrm{Q} & =160 \text { buah }
\end{aligned}
$$


Dari hasil analisa alternatif pembangkit desain akan didapatkan $(6 \times 5 \times 3 \times 3 \times 2)=$ 540 alternatif produk. Kemudian dilakukan penyeleksian terhadap alternatif-alternatif tersebut, dimana dilakukan dengan dua tahap penyeleksian. Seleksi pertama dilakukan oleh para pakar (dengan penilaian performansi untuk masing-masing kriteria diberikan rating antara 0-100) untuk mengetahui nilai dari 540 alternatif produk yang telah didapatkan. Sedangkan seleksi kedua dilakukan dengan penyebaran kuisioner kepada para konsumen, dimana dalam tahap ini disebarkan sebanyak 10 kuisioner.

Dari hasil penyeleksian tahap pertama diperoleh 5 nilai tertinggi (untuk perhitungan dapat dilihat dalam lampiran VII) yaitu sebagai berikut :

$$
\begin{aligned}
& \text { Alternatif I : DJLPS } \quad \mathrm{v}=2,08413421 \\
& \text { Alternatif II : BILQS } \quad \mathrm{v}=2,072807393 \\
& \text { Alternatif III : BKMPS } \mathrm{v}=2,039553799 \\
& \text { Alternatif IV : EKMOS } \mathrm{v}=1,986440419 \\
& \text { Alternatif V : FJNPS } \mathrm{v}=1,91656563
\end{aligned}
$$

Berikut adalah kombinasi-kombinasi baru yang direkomendasikan dari gabungan alternatif yang disebutkan diatas. Alternatif yang dimunculkan dianggap telah memenuhi persyaratan sebagai desain perancangan peningkatan kualitas spring bed tipe romano. Ciri-ciri rancangan tiap alternatif :

1. Desain Awal

- Model sandaran AM 1 (A)

- Warna kain cover biru kombinasi kuning

- Tebal busa $8 \mathrm{~cm}$

- Jumlah pegas 140 buah

- Jenis kain cover kain titan

\section{Alternatif 1}

- Model sandaran AM 4 (D)

- Warna kain cover krem kombinasi coklat

- Tebal busa $7 \mathrm{~cm}$

- Jumlah pegas 140 buah

- Jenis kain cover kain rayon

\section{Alternatif II}

- Model sandaran AM 2 (B)

- Warna kain cover hijau kombinasi kuning

- Tebal busa $7 \mathrm{~cm}$

- Jumlah pegas 150 buah

- Jenis kain cover kain rayon

\section{Alternatif III}

- Model sandaran AM 2 (B)

- Warna kain cover putih kombinasi pink

- Tebal busa $8 \mathrm{~cm}$

- Jumlah pegas 140 buah

- Jenis kain cover kain rayon

\section{Alternatif IV}

- Model sandaran AM 5 (E)

- Warna kain cover putih kombinasi pink

- Tebal busa $8 \mathrm{~cm}$

- Jumlah pegas 130 buah

- Jenis kain cover kain rayon

\section{Alternatif V}

- Model sandaran AM 6 (F)

- Warna kain cover krem kombinasi coklat

- Tebal busa $9 \mathrm{~cm}$

- Jumlah pegas 140 buah

- Jenis kain cover kain rayon 


\section{E. KESIMPULAN}

Dari hasil analisa perhitungan dan perencanaan peningkatan kualitas spring bed tipe romano di "UD.Dominico" Pasuruan, diperoleh alternative Berdasarkan dari analisa kebutuhan dan analisa fungsi, maka untuk mendapatkan produk spring bed yang diinginkan terdapat 3 macam elemen yang dibutuhkan, yaitu : Elemen Bentuk, Elemen Bahan, Elemen Warna. Dari hasil penyeleksian tahap pertama diperoleh 5 nilai tertinggi (untuk perhitungan dapat dilihat dalam lampiran VII) yaitu sebagai berikut :

Alternatif I : DJLPS $v=2,08413421$

Alternatif II : BILQS $v=2,072807393$

Alternatif III : BKMPS $\mathrm{v}=2,039553799$

Alternatif IV : EKMOS v $=1,986440419$

Alternatif $\mathrm{V}:$ FJNPS $\mathrm{v}=1,91656563$

Pembangkit alternatif desain yang akan dimunculkan sebagai berikut :dapat disimpulkan bahwa :

1. Desain alternatif terbaik dari spring bed yang direkomendasikan adalah alternatif I, dengan rancangan alternatif sebagai berikut :Model Sandaran AM 4

- Warna Kain Cover Krem kombinasi Coklat

- Tebal Busa $7 \mathrm{~cm}$

- Jumlah Pegas 140 buah

- Jenis Kain Cover kain Rayon

(Gambar dapat dilihat pada lampiran VIII)

3. Peningkatan nilai (value), performansi dan implementasi biaya yang diperoleh adalah:

\begin{tabular}{|c|c|c|}
\hline \multirow{2}{*}{ keterangan } & \multicolumn{2}{|c|}{ Alternatif Desain } \\
\cline { 2 - 3 } & $\begin{array}{c}\text { Desain } \\
\text { Awal }\end{array}$ & $\begin{array}{r}\text { Desain } \\
\text { Usulan }\end{array}$ \\
\hline Value & 1 & 1,5288 \\
\hline $\begin{array}{c}\text { Peningkatan } \\
\text { value (\%) }\end{array}$ & - & $15,28 \%$ \\
\hline $\begin{array}{c}\text { Performansi } \\
\text { Peningkatan } \\
\text { Performansi } \\
\text { (\%) }\end{array}$ & 42,2395 & 51,1842 \\
\hline Biaya & $\begin{array}{c}\text { Rp. } \\
\text { Rp. }\end{array}$ \\
\hline $\begin{array}{c}\text { Peningkatan } \\
\text { Biaya }\end{array}$ & - & 21,1762 \\
& 895.000 & 915.000 \\
\hline
\end{tabular}

\section{DAFTAR PUSTAKA}

Benjamin, Ostrofsky, 1977, "Design Planning and Development Methodology", Prentice-Hall.

Cross, Nigel, 1990, "Engineering Design Methods", John Wiley and Sons, Chichester, New York.

Heller, Edward, D. "Value Management, Value Engineering and Cost Reduction", Advison - Wesley - Publishing Company.

Pieter, George, E. "Engineering Design A Materials and Processing Approach", First Metric Edition.

Milles, Lawrence, D, "Techniauses Of Value Analysis and Engineering", Advison Wesley - Publishing Company. 
Fery Yulianto, Penerapan Rekayasa Nilai Pada Produk Spring Bed Tipe Romano

Permadi, Bambang, S. SE, 1992, " $A H P$ ", Pusat Antar Universitas - Studi Ekonomi Universitas Indonesia Jakarta.

Retno, Dyah, P. Ir, MT, 1999, "Diktat Rekayasa Nilai", FTI - Universitas Muhammadiyah Malang.

Retno, Dyah, P. Ir, MT, 2001, "Penerapan Studi Rekayasa Nilai Pada Perencanaan Runer", FTI - TI - ITS Surabaya.

Singarimbun, Masri dan Effendi, Sofyan, 1989, "Metode Penelitian Survey", Penerbit LP3ES Jakarta.

Zimmerman W. Larry and Hart D. Glend, "Value Engineering A Practical Approach For Owners, Designers and Contractors", CBS Publisher and Distributor. 